\title{
PARASITISM OF TOMATO FRUITWORM LARVAE IN PROCESS TOMATOES AT PUKEKOHE
}

\author{
G.P. WALKER ${ }^{1}$, T.J.B. HERMAN ${ }^{2}$, M.S. QURESHI ${ }^{3}$, S. WINKLER ${ }^{1}$ \\ and A.R. WALLACE ${ }^{4}$ \\ ${ }^{1}$ Crop \& Food Research, Private Bag 92169, Auckland, New Zealand \\ ${ }^{2}$ Fruitfed Supplies, P.O Box 322, Hastings, New Zealand \\ ${ }^{3}$ Central Queensland University, Plant Sciences Group, North Rockhampton, \\ Qld 4702, Australia \\ ${ }^{4}$ Crop \& Food Research, Private Bag 4704, Christchurch, New Zealand \\ Corresponding author: walkerg@crop.cri.nz
}

\begin{abstract}
A process tomato trial was undertaken at Pukekohe to investigate the interactions between tomato fruitworm, Helicoverpa armigera, and its larval parasitoids - the accidentally introduced generalist, Meteorus pulchricornis, and the introduced specialists, Cotesia kazak and Microplitis croceipes. Total mortality of larvae caused by parasitism was $75 \%$, with M. pulchricornis, the dominant parasitoid, reared from $54 \%$ of parasitised larvae, and C. kazak and M. croceipes reared from $33 \%$ and $13 \%$ respectively. Cotesia kazak attacked smaller larvae than the other two species and was able to survive in the presence of the entomopathogenic fungus Zoophthora radicans late in the crop. These results contrast with those for corresponding parasitism in Hawke's Bay where C. kazak is very dominant. It is concluded that the availability of alternative hosts in areas like Pukekohe is causing the displacement of $C$. kazak there but that this is having little impact on biocontrol of this pest in tomatoes.

Keywords: Helicoverpa armigera, Meteorus pulchricornis, Cotesia kazak, Microplitis croceipes, Zoophthora radicans.
\end{abstract}

\section{INTRODUCTION}

Tomato fruitworm (TFW), Helicoverpa armigera (Hübner) (Lepidoptera: Noctuidae), is the key pest of processing tomatoes in the major growing regions of Hawke's Bay and Gisborne, where it damages up to $30 \%$ of the fruit in unsprayed late season crops (Walker \& Cameron 1990). An integrated pest management (IPM) programme for outdoor tomatoes has been successfully implemented and is based on an economic action threshold of one larva per plant, scouting methods and establishment of larval parasitoids of TFW (Cameron et al. 2001).

The parasitoids attacking TFW larvae include the two introduced specialist species, Cotesia kazak Telenga (Hymenoptera: Braconidae) and Microplitis (=Glabromicroplitis) croceipes (Cresson) (Hymenoptera: Braconidae) (Walker \& Cameron 1989). These parasitoids attack small larvae, which are normally killed before they can locate and damage tomato fruit (Cameron et al. 2001). These parasitoids increased larval parasitism in process tomatoes in Hawke's Bay from $<1 \%$ (caused by a native Rogas sp.) before their deliberate introduction to 60-80\% by 1989 (Walker \& Cameron 1989). Cotesia kazak has remained the dominant parasitoid in process tomatoes in Hawke's Bay, parasitising 39-73.5\% of all collected larvae from 1990 to 2003 (Berry \& Walker 2004). A third accidentally introduced larval parasitoid, Meteorus pulchricornis (Wesmael) (Hymenoptera: Braconidae), was first reared from TFW larvae collected in tomato crops in Hawke’s Bay in February 1997 (Berry \& Walker 2004). This species has an extremely wide host range, being recovered from 21 species from 
eight lepidopteran families in New Zealand (Berry \& Walker 2004). However, the arrival of M. pulchricornis appears to be having a minimal impact on C. kazak in process tomatoes in Hawke's Bay. For example, in 2003 90\% of parasitised larvae collected from process tomato crops were parasitised by $C$. kazak, $8 \%$ by $M$. croceipes and just $2 \%$ by $M$. pulchricornis (Berry \& Walker 2004). Very similar patterns were observed for Hawke's Bay tomatoes in the 2002 and 2004 seasons (T.J.B. Herman \& G.P. Walker, unpubl. data). This minimal impact may be due to the restricted number of alternative hosts available as a reservoir for M. pulchricornis (Berry \& Walker 2004). This is because alternative host plants near tomato crops are minimised to control virus vectors (Herman 1995) and to maintain crop hygiene, which in turn reduces the abundance of lepidopteran species present. However, research has subsequently shown that M. pulchricornis is becoming an important component of the hymenopteran parasitoid fauna, being reared from three of the four lepidopteran families collected in a survey in vegetables and associated weeds at Pukekohe (Walker et al. 2004). Results from that survey indicated that $M$. pulchricornis might be competitively displacing the introduced specific parasitoids of TFW, with $89 \%$ of all parasitised larvae collected from various vegetables and weeds being parasitised by $M$. pulchricornis.

This study was undertaken to investigate the interactions between TFW and its larval parasitoids in tomatoes grown at Pukekohe, where numerous alternative hosts were available for M. pulchricornis.

\section{METHOD}

A tomato trial was planted at Pukekohe Research Centre, South Auckland $\left(174^{\circ} 5^{\prime} \mathrm{E}, 37^{\circ} 10^{\prime} \mathrm{S}\right)$, on 4 December 2003 . The trial area consisted of 800 plants in five beds ( $1.5 \mathrm{~m}$ wide) with two rows of tomatoes per bed and plants spaced every $0.75 \mathrm{~m}$ of row (an area of $450 \mathrm{~m}^{2}$ ). The cultivar grown was a disease-resistant standard processing tomato cultivar (A. Kale, pers. comm.) and the crop was managed without insecticide applications. When TFW eggs and larvae were first observed on 10 February 2004, weekly sampling for TFW larvae commenced, and was continued for 11 weeks until 20 April. Sampling consisted of visual inspection of a plant for 60 seconds, with four to eight plants sampled in each of the five beds. A plant was sampled every $7 \mathrm{~m}$ along a bed, and in subsequent weeks sampling began $2 \mathrm{~m}$ further along the bed to ensure that the same plants were not repeatedly sampled. All TFW larvae sighted on the 20-40 plants, or a representative sample of at least 35 up to a maximum of 60 larvae, were collected.

Larvae were placed individually into plastic tubes containing a general-purpose insect diet (Singh 1983) and plugged with cotton wool. Each collection was transported to the Mt Albert Research Centre where the larval instar of each caterpillar was immediately recorded. The collections were held in a laboratory at ambient temperatures with natural light and assessed every 2-3 days to record the fate of larvae, which was determined as (1) unparasitised (TFW pupa), (2) parasitised, (3) diseased or (4) dead of unknown cause. Parasitised larvae were maintained for cocoon formation, parasitoid adult eclosion and identification. Larvae showing symptoms of infection by an entomopathogenic fungus (producing primary conidia) were sent to Dr Travis Glare (AgResearch, Lincoln) for identification. Note that while the instar of each larva was recorded at the time of collection, it does not indicate the instar in which parasitism occurred but does provide an upper boundary as to the larval stage attacked.

Counts of the fate of the TFW larvae collected on each sampling occasion were analysed, using a log-linear model (McCullagh \& Nelder 1989) with Poisson error variance (and heterogeneity estimated from the data), to estimate proportions of each instar that were parasitised and to compare the fate of larvae.

\section{RESULTS}

At Pukekohe, 425 TFW larvae were collected during 11 weeks of sampling. After week 1, levels of infestation were relatively high, ranging from 1.0 to 2.2 larvae per plant. The fate of larvae is presented in Table 1, with 38 larvae assessed as dead of 
unknown causes and four parasitised larvae from which no parasitoid emerged. Meteorus pulchricornis was the dominant parasitoid species, being reared from $54 \%$ of the parasitised larvae, while 33\% produced C. kazak and 13\% produced M. croceipes. Parasitism was generally high, with mortality caused by parasitism being greater than $70 \%$ until week 9 , apart from week 1 when only a small number of larvae were collected. From week 9 onwards, mortality caused by the entomopathogenic fungus, Zoophthora radicans, complicated the situation. If dead larvae that were infected by $Z$. radicans are omitted (because we do not know whether or not they were parasitised) overall mortality from parasitism was 74.6\% (62\% from Week 9 onwards).

TABLE 1: Fate of Helicoverpa armigera larvae collected from tomatoes at Pukekohe Research Centre in 2004.

\begin{tabular}{|c|c|c|c|c|c|c|c|c|}
\hline Date & Week & $\begin{array}{l}\text { Unpara- } \\
\text { sitised }\end{array}$ & $\begin{array}{c}\text { C. } \\
\text { kazak }\end{array}$ & $\begin{array}{l}\text { M. cro- } \\
\text { ceipes }\end{array}$ & $\begin{array}{l}\text { M. pulch- } \\
\text { ricornis }\end{array}$ & $\begin{array}{c}Z \mathrm{Z} \\
\text { radi- } \\
\text { cans }\end{array}$ & Dead $^{1}$ & Total \\
\hline 10 Feb & 1 & 7 & 0 & 2 & 3 & & 0 & 12 \\
\hline 17 Feb & 2 & 11 & 12 & 12 & 3 & & 0 & 38 \\
\hline 25 Feb & 3 & 12 & 15 & 8 & 19 & & 2 & $60^{2}$ \\
\hline 3 Mar & 4 & 9 & 3 & 3 & 32 & & 5 & 52 \\
\hline $10 \mathrm{Mar}$ & 5 & 9 & 4 & 3 & 15 & & 5 & 36 \\
\hline 16 Mar & 6 & 6 & 6 & 3 & 20 & & 4 & 39 \\
\hline 23 Mar & 7 & 4 & 5 & 0 & 29 & & 6 & 44 \\
\hline $30 \mathrm{Mar}$ & 8 & 6 & 10 & 2 & 11 & & 6 & 35 \\
\hline $7 \mathrm{Apr}$ & 9 & 8 & 13 & 1 & 8 & 3 & 1 & 34 \\
\hline $16 \mathrm{Apr}$ & 10 & 12 & 7 & 0 & 4 & 9 & 6 & 38 \\
\hline $20 \mathrm{Apr}$ & 11 & 7 & 11 & 0 & 0 & 16 & 3 & 37 \\
\hline Total & & 91 & 86 & 34 & 144 & 28 & 38 & 425 \\
\hline
\end{tabular}

${ }^{1}$ Cause of death unable to be determined.

${ }^{2}$ Includes four parasitised by undetermined parasitoid species.

At week 9 also, a new cohort of TFW larvae was present in the tomato trial, resulting in $88 \%$ of collected larvae being 1st or 2nd instar larvae that week, while over other weeks only $14 \%$ on average were from these instars.

Meteorus pulchricornis was reared from all collections apart from the last week, being identified from $60 \%$ of the parasitised larvae collected over the first 8 weeks. After week 8, M. pulchricornis was no longer dominant, being reared from only $27 \%$ of parasitised larvae (change significant, $\mathrm{P}<0.001$ ).

Cotesia kazak was reared from all collections apart from week 1. It was never the dominant parasitoid species except in the presence of $Z$. radicans in weeks 9 to 11 , when it was reared from $70 \%$ of parasitised larvae. Over the first eight weeks C. kazak was reared from only $25 \%$ of parasitised larvae. It is noteworthy that $C$. kazak was the only parasitoid species reared from the last collection (week 11) when mortality was mainly caused by $Z$. radicans (53\% of dead larvae killed by the fungus).

Microplitis croceipes was reared from few larvae in most weeks, accounting for only $13 \%$ of parasitism overall.

Other lepidopteran larvae collected from tomatoes during this trial period were seven Chrysodeixis eriosoma, four geometrids and two leafroller larvae. Meteorus pulchricornis was reared from one larva of C. eriosoma and from three geometrid larvae.

Instar analysis of TFW shows that $C$. kazak was the only parasitoid species reared from 1st instar larvae (6 of 13 1st instar larvae collected) and no parasitoids were reared from 5th instars. Cotesia kazak was the dominant species reared from 2nd instar larvae (63\% of parasitised larvae). It was commonly reared from 3rd instar larvae (38\%) but 
not from 4th instars. Meteorus pulchricornis was the dominant species reared from collected 3rd and 4th instar larvae (51 and 78\%). These differences were significant $(\mathrm{P}<0.001)$. In summary, all $C$. kazak parasitoids were reared from early instars (up to 3rd) of TFW, while $94 \%$ of $M$. croceipes and $90 \%$ of $M$. pulchricornis adults were reared from 3rd or 4th instar larvae (Table 2).

TABLE 2: Fate of different instars of Helicoverpa armigera larvae collected from tomatoes at Pukekohe Research Centre in 2004. For each fate, the percentage of larvae with that fate that were produced from each instar is shown, i.e. row totals over instars sum to $100 \%$.

\begin{tabular}{lcccccc}
\hline \multirow{2}{*}{ Fate } & \multicolumn{7}{c}{ H. armigera instar at time of collection } & \multirow{2}{*}{ (Total no.) } \\
\cline { 2 - 6 } & 1st & 2nd & 3rd & 4th & 5th & \\
\hline C. kazak M. croceipes & 7 & 34 & 59 & 0 & 0 & $(86)$ \\
M. pulchricornis & 0 & 6 & 44 & 50 & 0 & $(34)$ \\
Z. radicans & 0 & 10 & 48 & 42 & 0 & $(144)$ \\
Unparasitised $^{1}$ & 7 & 11 & 79 & 7 & 0 & $(28)$ \\
\hline (Total no.) & $(13)$ & $(66)$ & $(200)$ & $(98)$ & $(6)$ & $(383)$ \\
\hline
\end{tabular}

${ }^{1}$ H. armigera pupa formed.

\section{DISCUSSION}

The generalist parasitoid $M$. pulchricornis was the dominant TFW larval parasitoid in the tomato trial at Pukekohe in 2004, accounting for $60 \%$ of parasitised larvae over the main sampling period (weeks 1 to 8). However, this dominance was not as great as reported in the previous year at the Pukekohe Research Centre when M. pulchricornis was reared from $89 \%$ of all parasitised TFW larvae collected from vegetable crops (principally from yacon and potatoes) and weeds in the same area (Walker et al. 2004). In the 2003 survey M. pulchricornis was recovered from all seven plant species infested by TFW, but $C$. kazak was only recovered from yacon and turnip while $M$. croceipes was reared from larvae collected from yacon, potato and black nightshade. Tomatoes were not grown at the Pukekohe Research Centre that season. This may suggest that the specialist parasitoids are possibly more successful in tomatoes, the main host of TFW, than in other crops, while M. pulchricornis is more successful in searching over a greater area and variety of plant species. The TFW larval populations in the tomato trial were much higher than on other adjacent crops and weeds (G.P. Walker, pers. observ.). Specialist parasitoids may be more efficient at utilising single host species than generalists and this might explain the reduction in the dominance of $M$. pulchricornis in the tomato crop at Pukekohe in 2004 compared with other crops in 2003.

In recent laboratory studies it has been found that $C$. kazak is able to utilise TFW larvae from neonate stage upwards, while M. pulchricornis prefers larvae greater than 24 hours old (G.P. Walker, unpubl. data). Our laboratory studies also show that at $19^{\circ} \mathrm{C}$ C. kazak develops from egg to adult slightly more quickly than M. pulchricornis (19 and 20 days respectively; $\mathrm{P}<0.001$ using the Kolmogorov-Smirnov non-parametric test), while both these species develop considerably faster than $M$. croceipes, which takes 25 days. With these physiological advantages we might expect $C$. kazak to be the dominant parasitoid of TFW in the field. This has been shown to be the case in Hawke's Bay tomato crops (Berry \& Walker 2004) but this dominance was not shown in our study at Pukekohe.

Microplitis croceipes was relatively common in the Pukekohe trial whereas previous surveys have indicated that this species was only established on the East Coast of the North Island (Walker \& Cameron 1989) and the North Island volcanic plateau (Herman \& Davidson 2000) and rarely found in other regions (Walker et al. 2004). In the present study, C. kazak was the only parasitoid species recovered when $Z$. radicans infection 
was the most common mortality factor. This suggests that $C$. kazak is able to survive during an epizootic of $Z$. radicans. Perhaps its ability to utilise smaller larvae and develop faster than the other two parasitoid species makes it better able to utilise 'sick' (infected) larvae as hosts. This view is supported by C. kazak emerging from three 'diseased larvae' in week 11.

Overall, mortality caused by parasitism was $75 \%$ in the trial at Pukekohe Research Centre, which is slightly higher than levels of total parasitism in Hawke's Bay tomatoes over the last three years (71\% in 2002 and 65\% in 2003 and 2004 (T.J.B Herman \& G.P. Walker, unpubl. data)). It is concluded that the availability of alternative hosts in areas like Pukekohe is causing the displacement of $C$. kazak as the dominant parasitoid of $H$. armigera, but that this is having little impact on the biocontrol of this pest in tomatoes.

Despite this apparent continuing biocontrol of TFW, there may be an economic impact for growers if $C$. kazak is displaced. This is because $C$. kazak normally kills larvae before they damage tomato fruit, emerging and causing the death of its host at the small 4th instar stage. Meteorus pulchricornis, by contrast, emerges and kills its host at a larger size (large 4th instar stage). This allows larvae parasitised by M. pulchricornis to cause some major damage to tomato fruit (G.P. Walker, pers. observ.). Consequently, in areas where M. pulchricornis is dominant, this species may disrupt the tomato IPM programme, which relies on C. kazak killing the majority of larvae before they damage fruit.

\section{ACKNOWLEDGEMENTS}

We thank Alan Kale for supplying tomato seed and advice on growing the crop at Pukekohe, and Rene van Tilburg for managing the crop at Pukekohe. We also thank Dr Travis Glare (AgResearch) for identifying the entomopathogenic fungi. Carol Curtis and Paul Barnett assisted with field collections at Pukekohe. We also thank Fruitfed Supplies' scouts for collecting and processing TFW larvae in Hawke’s Bay. This work was funded by the Foundation for Research, Science and Technology.

\section{REFERENCES}

Berry JA, Walker GP 2004. Meteorus pulchricornis (Wesmael) (Hymenoptera: Braconidae: Euphorinae): an exotic polyphagous parasitoid in New Zealand. New Zealand Journal of Zoology 31: 33-44.

Cameron PJ, Walker GP, Herman TJB, Wallace AR 2001. Development of Economic Thresholds and Monitoring Systems for Helicoverpa armigera (Lepidoptera: Noctuidae) in tomatoes. Journal of Economic Entomology 94(5): 1104-1112.

Herman TJB 1995. Integrated Pest Management for Process Tomatoes. IPM Manual 5. Crop \& Food Research, Lincoln, New Zealand.

Herman TJB, Davidson MM 2000. Introduction and establishment of Microplitis croceipes, a larval parasitoid of Heliothis, in North Island pine forests. New Zealand Plant Protection 53: 328-333.

McCullagh P, Nelder JA 1989. Generalized linear models (2nd edition). Chapman and Hall, London, United Kingdom.

Singh P 1983. A general-purpose insect diet mixture for rearing insects. Insect Science and its Application 4: 253-256.

Walker GP, Cameron PJ 1989. Status of introduced larval parasitoids of tomato fruitworm. Proceedings of the 42nd New Zealand Weed and Pest Control Conference: 229232.

Walker GP, Cameron PJ 1990. Pheromone trapping and field scouting for tomato fruitworm in tomatoes and sweet corn. Proceedings of the 43rd New Zealand Weed and Pest Control Conference: 17-20.

Walker GP, Qureshi MS, Wallace AR 2004. Parasitism of lepidopteran larvae collected from vegetables and associated weeds at Pukekohe. New Zealand Plant Protection 57: 1-7. 